\title{
A comparison of 5-year administration of cyproterone acetate or leuprolide acetate in combination with estradiol in transwomen
}

\section{Giulia Gava, Ilaria Mancini, Stefania Alvisi, Renato Seracchioli and Maria Cristina Meriggiola}

Gynecology and Physiopathology of Human Reproduction, Department of Medical and Surgical Sciences (DIMEC), S. Orsola-Malpighi Hospital, University of Bologna, Bologna, Italy
Correspondence should be addressed to G Gava

Email

giulia.gava2@unibo.it

\begin{abstract}
Objective: The impact of different combinations of long-term gender-affirming hormone therapy (GAHT) in transwomen (TW) is largely unknown. To assess the effects of 5-year administration of cyproterone acetate (CPA) or leuprolide acetate (Leu) plus transdermal or oral estradiol (E).

Design: Cohort study based on prospectively collected data. Fifty TW received $50 \mathrm{mg}$ CPA daily orally $(n=25 ; \mathrm{CPA}+\mathrm{E}$ group) or $3.75 \mathrm{mg}$ Leu i.m. monthly ( $n=25$; Leu+E group) with 1 or $2 \mathrm{mg}$ E daily for 5 years. Reproductive hormones, biochemical and anthropometric parameters, body composition and bone mineral density (BMD) were assessed. Results: LH, FSH and total testosterone levels were similarly and significantly suppressed in both groups. Prolactin increased only in the $\mathrm{CPA}+\mathrm{E}$ group $(P=0.002)$. Fasting insulin resistance and glucose progressively increased in the $\mathrm{CPA}+\mathrm{E}$ group only (treatment $\times$ time effect $P=0.002$ and $P=0.043$, respectively). Total cholesterol increased more in the Leu+E group than in the CPA+E group and HDL-cholesterol decreased in the CPA+E group (time $\times$ treatment interaction effect, $P=0.007)$. Lumbar and total body BMD increased in both groups after 3 years. No serious adverse events were recorded.

Conclusions: Both regimens were effective in suppression of T production. CPA+E worsened the metabolic profile with a slight increase in PRL levels. All subjects presented an increase in BMD regardless of treatment. These preliminary data could have clinical implications in the choice of GAHT, in particular for those TW not requiring genderaffirming surgery.
\end{abstract}

\section{Introduction}

The aim of gender-affirming medical and/or surgical interventions (GAMI/GASI) in transgender persons is the relief of dysphoria and improvement of quality of life. Gender-affirming hormone therapy (GAHT) is an important tool for some gender-non-conforming individuals to acquire the phenotypic features of the desired gender $(1,2)$. In transwomen (TW), the Endocrine Society guidelines recommend the association of estradiol (E) with anti-androgens (3). The goal is to suppress endogenous male hormones and the development of female secondary sexual characteristics. In Europe, the most widely used anti-androgenic compound is cyproterone acetate (CPA) (4), whereas in the US where it is not available other agents such as spironolactone or GnRH analogues are commonly used in combination with E (3).

CPA is a progestin with anti-androgenic activity working both through the suppression of gonadotropins and thereby testosterone secretion and in competition with androgens for binding to androgen receptors. TW

Published by Bioscientifica Ltd. 
are usually treated with 50-100 mg/day of CPA, but even lower doses may be effective due to its accumulation in the subcutaneous tissue (3). Available literature shows that despite long-term intake and sometimes highly uncontrolled doses, the overall safety of these regimens is high (5). In hormone-treated TW increased mortality is mainly due to non-hormone-related causes (5). However, adverse effects are reported during CPA administration such as weight gain, hepatotoxicity, dosedependent sedative effects and depression $(2,6)$. Episodes of hepatotoxicity have been documented but after higher doses of CPA (100-300 mg) in elderly treated for cancer for long periods (7). Transgenders are a different population, with their own characteristics and risk factors to which is difficult to apply these data. However, the elevation of liver enzymes has been also described in the trans population after many years of CPA treatment, even though it is unclear whether the liver alterations were a consequence of CPA or of estrogens $(6,8)$.

$\mathrm{GnRH}$ analogues are used in combination with $\mathrm{E}$ in TW; long-acting formulations (monthly or threemonthly injections) are used to suppress hypothalamichypophysis-gonadal axis in adult TW and in adolescents to block pubertal development (9). The most commonly used GnRH analogues are leuprolide acetate (Leu), goserel in acetate or triptorelin pamoate, although there are no comparative studies of these molecules in TW (10) and the cost of long-acting GnRH agonists often prohibits their use in the trans population.

In a previous study, we reported that 1-year administration of transdermal estradiol hemihydrate (TE) with CPA or Leu in TW are both effective and safe but with different effects on HDL-cholesterol and on PRL levels suggesting a better profile of Leu over CPA in the short time (11). Therefore, the aim of this study was to compare the two regimens over a longer period of time (5 years).

\section{Subjects and methods}

Subjects diagnosed with gender incongruence (GIC) according to ICD-11 (12) and with a GAHT duration of 5 years were included. At their first visit to our centre subjects signed informed consent to GAMI and to the anonymous use of data for clinical and research purposes. For this reason, clinical data are routinely prospectively collected for all subjects in their charts at the time of each in-clinic visit. At the time of the first GAHT prescription, options were explained to subjects and, as both CPA and Leu are currently considered standard GAHT, both treatments were explained to the subjects and TW were assigned to one of the two treatments according to an alternate sequence list.

The primary endpoint of this study was the evaluation of the metabolic profile in the two treatments groups over 5 years of time. Secondary endpoints were the assessment the hormonal, anthropometric and bone profiles of CPA or Leu in combination with E over the 5-year study period.

Inclusion criteria were as follows: diagnosis of GIC, signed informed consent, cross-sex hormone naïve before GAHT prescription. Exclusion criteria: GASI prior to treatment or during the study, switch to a different hormonal treatment during the follow-up period. Subjects were also excluded if any of the following data were missing: clinical and laboratory data at baseline or at yearly visits or if DXA evaluations at baseline and at years 1, 3 and 5 were not performed. TW with diabetes and those taking cholesterol-lowering drugs or anti-psychotics were also excluded.

All demographic and clinical information was collected by consulting patient medical records. Enrollment commenced in April 2019 and ended in February 2020.

At baseline and yearly thereafter, serum total testosterone (TT), E, LH, FSH, prolactin (PRL), sex hormone-binding globulin (SHBG), haematocrit (Ht), haemoglobin $(\mathrm{Hb})$, fasting glucose, fasting insulin, total cholesterol (Tot-Chol), high- and low-density lipoproteins (HDL and LDL), triglycerides (TG), aspartate and alanine aminotransferases (AST and ALT), prothrombin time (PT), activated partial thromboplastin time (aPTT), osteocalcin (OC), parathyroid hormone (PTH), bone alkaline phosphatase (BAP) and 25-hydroxyvitamin D (Vit D) were measured. Venous blood samples were obtained after overnight fasting. All samples were analysed at Central Laboratory of S. Orsola Malpighi Hospital (Bologna, Italy). Estradiol was measured using Access Sensitive Estradiol immnunoessay with an interassay coefficient of variation $(\mathrm{CV})$ of $7 \%$ and a lower limit of quantitation (LOQ) of $9.4 \mathrm{pg} / \mathrm{mL}$. TT was measured using a competitive immunoassay with an interassay $\mathrm{CV}$ lower than $6 \%$ and an LOQ of $0.1 \mathrm{ng} / \mathrm{mL}$. LH, FSH and SHBG were measured by competitive immunoassay with interassay CV less than 10,7 and $8 \%$ respectively and a LOQ of $1.2 \mathrm{mU} / \mathrm{mL}, 1.3$ $\mathrm{mU} / \mathrm{mL}$ and $13 \mathrm{nmol} / \mathrm{L}$. Also other serum metabolites and hormones were measured using a competitive immunoassay in the same central laboratory (13). Fasting insulin resistance (HOMA-IR) was calculated using the 
formula HOMA-IR $=($ fasting insulin in $\mu \mathrm{U} / \mathrm{mL} \times$ fasting glucose in $\mathrm{nmol} / \mathrm{L}) / 22.5$.

Blood pressure and anthropometric examinations performed at least yearly included assessment of weight, stature and waist and hip circumferences, according to standardised procedures.

At baseline and during follow-up (after 12 months and then every 24 months), body composition and bone mineral density (BMD) were measured by dual X-ray absorptiometry (DXA) using the Hologic 49159 densitometer and standard QDR body composition software (Model QDR4500W, Software Level 112, Hologic Spine, Hologic, Bed- ford, MA, USA).

This study was approved by the Medical Ethics Committee of S. Orsola Hospital, Bologna, and all subjects gave written informed consent.

\section{Statistical analysis}

All continuous data are expressed as mean and standard deviation of the mean and all categorical data were expressed by frequency rate and percentage. The Kolgomorov-Smirnov test was used to assess the normality of distributions. When data were normally distributed, parametric Student's $t$-test was used to assess differences between two groups. Otherwise, the MannWhitney $U$-test was used. Pearson's nonparametric chisquared test or Fisher's nonparametric chi-squared test was performed to investigate the relationships between categoric variables.

A mixed-design ANOVA post hoc pairwise comparisons with Tukey's honest significance difference (HSD) test was conducted to compare the main effects and the interaction effect between type of treatment and time of treatment on clinical, laboratory and DXA parameters. To control for type I error related to multiple testing, the significance level was set at 0.01 . Statistical analysis was carried out using Statistical Package for the Social Sciences software, version 23.0 (SPSS Inc.).

\section{Results}

Eighty-eight TW who started treatment between September 2012 and January 2015 were potentially eligible and screened. According to our inclusion/ exclusion criteria, 38 subjects were not enrolled. The most common reason for exclusion was the missing data (29 subjects), followed by GASI during the 5 years follow-up (nine subjects). Excluded subjects at baseline presented similar age $(29.9 \pm 11.4$ years $)$ and BMI $(20.8 \pm 4.5)$ if compared to subjects included in the statistical analysis. The remaining 50 were enrolled and included in the data analysis. Oral CPA $50 \mathrm{mg} /$ day ( $n=25$; CPA+E group) or Leu at a monthly dose of $3.75 \mathrm{mg}$ i.m. injections $(n=25$; Leu+E group) were administered plus estradiol (1-2 mg/ day, transdermal estradiol (TE) or oral estradiol valerate $(\mathrm{EV}))$ for 5 years. The majority of subjects received TE: $80 \%$ in the CPA+E group (20/25) and $88 \%$ in Leu+E group (22/25). All participants were Caucasian. No subjects reported agonistic physical activity or long-lasting dietary restrictions. The anthropometric, clinical, biochemical and DXA baseline characteristics of all subjects enrolled in the study are summarised in Table 1 . No evidence of differences between the two groups was found at baseline.

\section{Hormonal parameters}

LH, FSH and TT were significantly decreased compared to baseline by year 1 of GAHT in both groups and remained suppressed throughout the study (Fig. 1). LH, FSH and TT presented similar trends between the two groups. E levels increased throughout the treatment period with estradiol remaining within the normal female range in both groups (range: 132.16-917.75 pmol/L and 117.47-1138.01 $\mathrm{pmol} / \mathrm{L}$ respectively for $\mathrm{CPA}+\mathrm{E}$ and $\mathrm{Leu}+\mathrm{E})$.

PRL showed a significantly different trend in the two groups increasing in $\mathrm{CPA}+\mathrm{E}$ and decreasing in Leu+E. In $\mathrm{CPA}+\mathrm{E}$ PRL levels were significantly increased by year $1(P=0.002)$ with no further increase by year 5 . SHBG increased in both groups, but significantly only in LEU+E with a significant treatment and time effect $(P=0.0004$ and $P=0.0018$, respectively).

\section{Biochemical and metabolic parameters}

Hematocrit and haemoglobin significantly decreased in both groups during the follow-up $(P \leq 0.0001)$ with a significant decrease in the first year of treatment, always remaining within the physiological range (Table 2). The decrease rate of $\mathrm{Ht}$ was similar between the two groups, whereas $\mathrm{Hb}$ showed a slight rebound after year 4 in Leu+E probably consequent to the slight increase in TT (Table 2). No significant changes in coagulative parameters and in the hepatic function were observed in either group.

Tot-Chol changes were different in the two groups $(P=0.007)$ increasing more in Leu+E than in CPA+E. HDLcholesterol showed a different trend in the two groups. In the post hoc analysis HDL-cholesterol decreased significantly in CPA+E in the first year and then re-increased 
Table 1 Baseline characteristics of the enrolled subjects in the two groups of subjects. Data are reported as mean \pm S.D.

\begin{tabular}{l}
\hline \\
\hline Age (years) \\
Smokers, $n$ (\%) \\
Ht (\%) \\
Hb (g/L) \\
AST (U/L) \\
ALT (U/L) \\
Total cholesterol (mmol/L) \\
HDL cholesterol (mmol/L) \\
LDL cholesterol (mmol/L) \\
TG (mmol/L) \\
Glucose (mmol/L) \\
Insulin (pmol/L) \\
HOMA-IR \\
Body weight (kg) \\
BMI (kg/m²) \\
Waist circumference (cm) \\
Hip circumference (cm) \\
WHR \\
Fat (\%) \\
Systolic BP (mm Hg) \\
Diastolic BP (mm Hg) \\
OC ( $\mu$ g/L) \\
PTH (pg/mL) \\
BAP (UI/L) \\
Lumbar BMD (g/cm²) \\
Total BMD (g/cm²) \\
FSH (UI/L) \\
LH (Ul/L) \\
E2 (pmol/L) \\
TS (nmol/L) \\
PRL (ng/mL) \\
SHBG (ug/mL) \\
\end{tabular}

\begin{tabular}{|c|}
\hline $\mathbf{C P A}+\mathbf{E}(n=25)$ \\
\hline $\begin{array}{c}31.1 \pm 8.9 \\
14(56)\end{array}$ \\
\hline $43.84 \pm 3.93$ \\
\hline $150.1 \pm 12.1$ \\
\hline $21.0 \pm 5.3$ \\
\hline $21.5 \pm 10.2$ \\
\hline $4.61 \pm 1.31$ \\
\hline $1.33 \pm 0.34$ \\
\hline $2.86 \pm 1.10$ \\
\hline $0.89 \pm 0.40$ \\
\hline $4.9 \pm 0.5$ \\
\hline $55.6 \pm 24.3$ \\
\hline $1.8 \pm 0.8$ \\
\hline $68.3 \pm 11.9$ \\
\hline $22.2 \pm 3.6$ \\
\hline $78.1 \pm 6.4$ \\
\hline $93.7 \pm 6.3$ \\
\hline $0.83 \pm 0.06$ \\
\hline $22.9 \pm 7.3$ \\
\hline $120 \pm 9$ \\
\hline $73 \pm 8$ \\
\hline $24.7 \pm 10.3$ \\
\hline $42.1 \pm 16.4$ \\
\hline $15.8 \pm 7.0$ \\
\hline $1.0 \pm 0.2$ \\
\hline $1.2 \pm 0.1$ \\
\hline $4.2 \pm 3.6$ \\
\hline $4.4 \pm 3.1$ \\
\hline $123.0 \pm 90.1$ \\
\hline $18.50 \pm 6.21$ \\
\hline $11.6 \pm 6.9$ \\
\hline $27.4 \pm 5.8$ \\
\hline
\end{tabular}

\begin{tabular}{|c|c|}
\hline Leu+E $(n=25)$ & $P$-value \\
\hline $32.5 \pm 12.5$ & 0.650 \\
\hline $13(52)$ & 0.999 \\
\hline $45.17 \pm 2.59$ & 0.163 \\
\hline $151.4 \pm 7.8$ & 0.658 \\
\hline $18.8 \pm 4.1$ & 0.110 \\
\hline $17.9 \pm 5.8$ & 0.195 \\
\hline $4.62 \pm 1.13$ & 0.964 \\
\hline $1.49 \pm 0.38$ & 0.134 \\
\hline $2.71 \pm 0.97$ & 0.611 \\
\hline $0.92 \pm 0.41$ & 0.844 \\
\hline $4.9 \pm 0.8$ & 0.881 \\
\hline $43.5 \pm 16.7$ & 0.061 \\
\hline $1.3 \pm 0.1$ & 0.070 \\
\hline $67.6 \pm 9.2$ & 0.819 \\
\hline $21.9 \pm 2.6$ & 0.744 \\
\hline $79.9 \pm 7.2$ & 0.524 \\
\hline $97.1 \pm 3.9$ & 0.080 \\
\hline $0.82 \pm 0.07$ & 0.579 \\
\hline $23.0 \pm 6.1$ & 0.142 \\
\hline $119 \pm 9$ & 0.696 \\
\hline $69 \pm 6$ & 0.066 \\
\hline $31.7 \pm 14.0$ & 0.075 \\
\hline $42.6 \pm 19.8$ & 0.915 \\
\hline $17.4 \pm 9.7$ & 0.549 \\
\hline $1.1 \pm 0.1$ & 0.359 \\
\hline $1.1 \pm 0.1$ & 0.268 \\
\hline $4.7 \pm 3.4$ & 0.418 \\
\hline $5.0 \pm 2.3$ & 0.459 \\
\hline $98.9 \pm 42.6$ & 0.238 \\
\hline $21.51 \pm 7.29$ & 0.147 \\
\hline $11.8 \pm 5.8$ & 0.874 \\
\hline $36.9 \pm 12.3$ & 0.065 \\
\hline
\end{tabular}

ALT, alanine aminotransferase; AST, aspartate aminotransferase; BAP, bone alkaline phosphatase; BP, blood pressure; CPA, cyproterone acetate; E2, estradiol; Hb, haemoglobin; HOMA-IR, homeostasis model assessment for fasting insulin resistance; Ht, haematocrit; Leu, leuprolide acetate; OC, osteocalcin; PRL, prolactin; PTH, parathyroid hormone; TS, testosterone; TG, triglycerides; Vit D, 25-hydroxyvitamin D; WHR, waist/hip ratio.

never returning to basal levels; whereas, in Leu+E, HDLcholesterol maintained an increasing trend over time with significant variations between baseline and years 3 and 5 ( $P=0.04$ and $P=0.047$, respectively). Triglycerides and LDL did not significantly change in either group.

The HOMA-IR showed a progressive and significant increase only in $\mathrm{CPA}+\mathrm{E}$, resulting in a significantly different trend in the two groups.

\section{Anthropometric parameters, body composition and blood pressure}

BMI showed a slight increase in both groups but without significant time and/or treatment effects. At baseline, $84 \%$ of TW had normal BMI with 16\% who were overweight in $\mathrm{CPA}+\mathrm{E}$ where as $88 \%$ had normal $\mathrm{BMI}$ and $12 \%$ were overweight in Leu+E. After 5 years $80 \%$ of TW had normal BMI, $16 \%$ were overweight and $4 \%$ obese in the
CPA+E group whereas 84\% had normal BMI and 16\% were overweight in Leu+E group. At 5-year follow-up, waist and hip circumferences and WHR did not change significantly in either group. Blood pressure did not show significant modifications in both groups over 5 years. Body composition, assessed through DXA, showed some non-significant variations in both groups: lean body mass decreased $(51.5 \pm 7.8$ to $45.9 \pm 3.6 \mathrm{~kg}$ and $51.5 \pm 7.1$ to $47.7 \pm 6.8$, respectively, for $\mathrm{CPA}+\mathrm{E}$ and Leu+E), and fat mass increased similarly in both groups $(16.1 \pm 6.6$ to $24.0 \pm 10.8 \mathrm{~kg}$ and $15.6 \pm 5.3$ to $24.6 \pm 9.2$, respectively, for CPA+E and Leu+E) (Table 3).

\section{Bone parameters}

Bone metabolism parameters (OC, PTH and BAP) did not change significantly in either group with no time or treatment effect. Vit D showed a slight but insignificant 

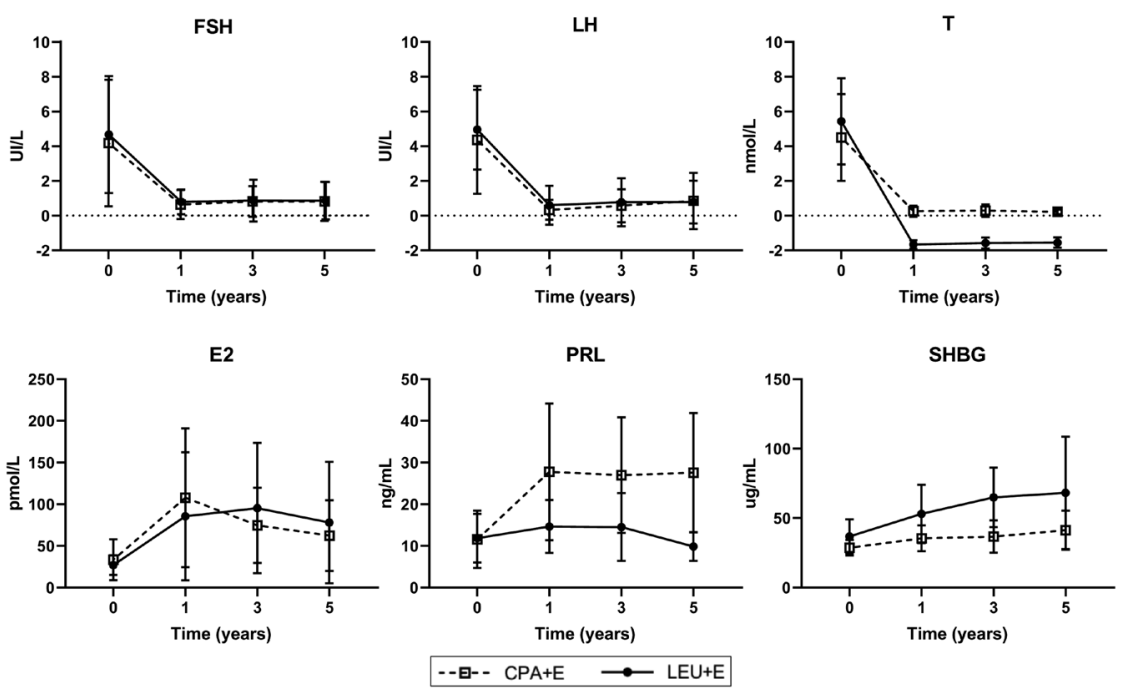

\section{Figure 1}

Variations of hormonal parameters during follow-up of GATH in the two groups of subjects. CPA, cyproterone acetate; Leu, leuprolide acetate; E2, estradiol; $\mathrm{T}$, testosterone; $\mathrm{PRL}$, prolactin. increase during the follow-up period, which may be due to the discontinuous use of the prescribed supplement.

DXA follow-up showed a significant and similar increase in both groups over time in the total body evaluation $(P=0.008)$. The post hoc analysis revealed that the variation in the lumbar and total body BMD occurred after 3 years of treatment in both groups $(P=0.004$ and $P=0.03$, respectively, for $\mathrm{CPA}+\mathrm{E}$ and $\mathrm{LEU}+\mathrm{E})$.

\section{Adverse events}

No death, myocardial infarction, stroke, venous thromboembolism or other adverse events were recorded during the follow-up in any subjects of either group. No subject required interruption or change of therapy.

\section{Discussion}

In this study, we compared the effects of 5-year administration of CPA or a Leu plus estradiol in TW to assess differences in the induced metabolic profile and in the safety of the two regimens.

The two regimens were similar in terms of gonadotropin and testosterone suppression and increase of E levels. No serious adverse event occurred in either group, but the $\mathrm{CPA}+\mathrm{E}$ group reported more adverse metabolic changes such as a decrease in HDL-cholesterol, increase in insulin resistance and in PRL levels while no adverse metabolic changes were detected in the Leu+E group except for a slight increase in total cholesterol due to increasing levels of HDL-cholesterol.

The two regimens were equally effective in the suppression of gonadotrophins throughout the study.
We previously reported a faster suppression of $\mathrm{LH}$ in subjects treated with Leu+E when compared to $\mathrm{CPA}+\mathrm{E}$ but at the end of 1 year the suppression was similar in the two groups (11) and in this follow-up study LH and FSH suppression remained stable throughout 5 years. SHBG increased in both groups but significantly only in LEU+E. It is well known that estrogen administration is associated with increased SHBG and, while Leu does not affect this estrogenic effect, CPA has been reported to decrease SHBG and this effect may have counteracted the effect of $\mathrm{E}$ (14).

We confirm previously reported data that PRL increase significantly after 12 months of CPA+E. This increase of PRL during CPA administration alone or combined with estrogens is well known and reported $(15,16)$. This finding further confirms that not only ethynylestradiol but also CPA may be involved in the PRL increase and in the rare cases of prolactinoma reported in these subjects $(17,18,19,20)$. However, in our cohort, there were no reports of prolactinoma development in TW in either group during the 5-year follow-up. In addition, it should be noted that the increase of PRL is already present at year 1 and remained stable throughout the follow-up.

In our cohort, HDL-cholesterol decreased in $\mathrm{CPA}+\mathrm{E}$, whereas it increased in Leu+E, leading to an increase in Tot-Chol in this group. Triglycerides and LDL showed no significant changes. The results from the $\mathrm{CPA}+\mathrm{E}$ group extend and confirm most of the previously published data by us and others that showed similar effects on cholesterol even if after shorter follow-ups $(11,21,22,23)$. These variations may be related to the residual androgenic effect of CPA (24). Only Ott et al. reported an increase of triglycerides, Tot-Chol and HDL-cholesterol in 89 TW treated with CPA, finasteride and EV or TE for 24-60 months (25). However, relevant differences can be noted 
Table 2 Hematologic, biochemical and metabolic parameters at baseline and during follow-up of GAHT in the two groups of subjects. Data are reported as mean \pm S.D.

\begin{tabular}{|c|c|c|c|c|c|c|c|c|c|c|c|}
\hline \multirow[b]{3}{*}{ Groups } & \multirow[b]{3}{*}{$n$} & \multirow[b]{3}{*}{ Baseline } & \multirow[b]{3}{*}{ Year 1} & \multirow[b]{3}{*}{ Year 3} & \multirow[b]{3}{*}{ Year 5} & \multicolumn{6}{|c|}{ Mixed-design ANOVA results } \\
\hline & & & & & & \multicolumn{2}{|c|}{ Time } & \multicolumn{2}{|c|}{ Treatment } & \multicolumn{2}{|c|}{ Time $\times$ treatment } \\
\hline & & & & & & $\mathrm{F}$ & $P$ & $\mathrm{~F}$ & $P$ & $\mathrm{~F}$ & $P$ \\
\hline $\mathrm{Ht}(\%)$ & & & & & & 46.01 & $<0.0001$ & 1.402 & 0.242 & 2.557 & 0.059 \\
\hline$C P A+E$ & 25 & $43.84 \pm 3.93$ & $40.94 \pm 2.47$ & $40.52 \pm 2.30$ & $40.09 \pm 2.95$ & & & & & & \\
\hline Leu + E & 25 & $45.17 \pm 2.59$ & $40.53 \pm 2.21$ & $41.06 \pm 2.28$ & $41.75 \pm 2.70$ & & & & & & \\
\hline $\mathrm{Hb}(\mathrm{g} / \mathrm{L})$ & & & & & & 46.93 & $<0.0001$ & 0.876 & 0.354 & 3.281 & 0.024 \\
\hline$C P A+E$ & 25 & $150.1 \pm 12.1$ & $138.9 \pm 7.3$ & $138.9 \pm 6.7$ & $134.3 \pm 9.9$ & & & & & & \\
\hline Leu + E & 25 & $151.4 \pm 7.8$ & $137.0 \pm 8.6$ & $139.6 \pm 7.3$ & $142.6 \pm 10.4$ & & & & & & \\
\hline AST (U/L) & & & & & & 0.855 & 0.418 & 0.182 & 0.671 & 1.143 & 0.335 \\
\hline$C P A+E$ & 25 & $21.0 \pm 5.3$ & $20.3 \pm 10.8$ & $18.5 \pm 9.7$ & $15.0 \pm 3.4$ & & & & & & \\
\hline Leu + E & 25 & $18.8 \pm 4.1$ & $21.6 \pm 11.5$ & $19.9 \pm 5.1$ & $20.2 \pm 4.8$ & & & & & & \\
\hline ALT (U/L) & & & & & & 2.099 & 0.114 & 0.066 & 0.797 & 1.702 & 0.171 \\
\hline$C P A+E$ & 25 & $21.5 \pm 10.2$ & $21.0 \pm 14.1$ & $17.0 \pm 7.9$ & $15.8 \pm 6.6$ & & & & & & \\
\hline Leu + E & 25 & $17.9 \pm 5.8$ & $20.1 \pm 11.0$ & $19.2 \pm 7.8$ & $17.9 \pm 8.5$ & & & & & & \\
\hline $\begin{array}{l}\text { Tot chol } \\
\qquad(\mathrm{mmol} / \mathrm{L})\end{array}$ & & & & & & 2.050 & 0.114 & 2.282 & 0.137 & 4.260 & 0.007 \\
\hline $\mathrm{CPA}+\mathrm{E}$ & 25 & $4.61 \pm 1.31$ & $4.46 \pm 0.83$ & $4.22 \pm 0.83$ & $4.60 \pm 1.08$ & & & & & & \\
\hline Leu + E & 25 & $4.62 \pm 1.13$ & $4.87 \pm 1.05$ & $4.88 \pm 1.12$ & $5.32 \pm 1.1$ & & & & & & \\
\hline $\mathrm{HDL}(\mathrm{mmol} / \mathrm{L})$ & & & & & & 1.948 & 0.130 & 1.060 & 0.002 & 6.722 & 0.0003 \\
\hline $\mathrm{CPA}+\mathrm{E}$ & 25 & $1.33 \pm 0.34$ & $1.15 \pm 0.21$ & $1.24 \pm 0.31$ & $1.27 \pm 0.25$ & & & & & & \\
\hline Leu + E & 25 & $1.49 \pm 0.38$ & $1.62 \pm 0.53$ & $1.65 \pm 0.48$ & $1.70 \pm 0.47$ & & & & & & \\
\hline LDL (mmol/L) & & & & & & 1.948 & 0.130 & 0.012 & 0.913 & 1.182 & 0.319 \\
\hline $\mathrm{CPA}+\mathrm{E}$ & 25 & $2.86 \pm 1.10$ & $3.04 \pm 0.97$ & $2.59 \pm 0.76$ & $3.03 \pm 1.17$ & & & & & & \\
\hline Leu + E & 25 & $2.71 \pm 0.97$ & $2.83 \pm 1.03$ & $2.79 \pm 1.02$ & $2.98 \pm 1.14$ & & & & & & \\
\hline TG (mmol/L) & & & & & & 0.285 & 0.792 & 0.175 & 0.677 & 0.059 & 0.981 \\
\hline $\mathrm{CPA}+\mathrm{E}$ & 25 & $0.89 \pm 0.40$ & $0.84 \pm 0.49$ & $0.89 \pm 0.55$ & $0.85 \pm 0.29$ & & & & & & \\
\hline Leu + E & 25 & $0.92 \pm 0.41$ & $0.92 \pm 0.45$ & $0.94 \pm 0.55$ & $0.97 \pm 0.51$ & & & & & & \\
\hline $\begin{array}{l}\text { Glucose } \\
\qquad(\mathrm{mmol} / \mathrm{L})\end{array}$ & & & & & & 1.286 & 0.284 & 0.001 & 0.981 & 2.804 & 0.043 \\
\hline $\mathrm{CPA}+\mathrm{E}$ & 25 & $4.9 \pm 0.5$ & $4.6 \pm 0.6$ & $4.8 \pm 0.3$ & $5.0 \pm 0.3$ & & & & & & \\
\hline Leu + E & 25 & $4.9 \pm 0.8$ & $4.9 \pm 0.5$ & $4.8 \pm 0.5$ & $4.7 \pm 0.5$ & & & & & & \\
\hline $\begin{array}{l}\text { Insulin } \\
\qquad \text { (pmol/L) }\end{array}$ & & & & & & 1.552 & 0.119 & 2.514 & 0.224 & 0.299 & 0.826 \\
\hline$C P A+E$ & 25 & $55.6 \pm 24.3$ & $60.42 \pm 38.9$ & $72.92 \pm 42.4$ & $60.42 \pm 36.1$ & & & & & & \\
\hline Leu + E & 25 & $43.5 \pm 16.7$ & $48.62 \pm 20.1$ & $44.45 \pm 22.9$ & $34.03 \pm 18.1$ & & & & & & \\
\hline HOMA-IR & & & & & & 1.213 & 0.306 & 12.80 & 0.0008 & 5.245 & 0.002 \\
\hline$C P A+E$ & 25 & $1.8 \pm 0.8$ & $1.7 \pm 1.2$ & $2.2 \pm 1.3$ & $2.6 \pm 1.5$ & & & & & & \\
\hline Leu + E & 25 & $1.3 \pm 0.5$ & $1.5 \pm 0.7$ & $1.4 \pm 0.8$ & $1.0 \pm 0.6$ & & & & & & \\
\hline
\end{tabular}

ALT, alanine aminotransferase; AST, aspartate aminotransferase; CPA, cyproterone acetate; Hb, haemoglobin; HDL, high-density lipoprotein cholesterol; $\mathrm{Ht}$, haematocrit; HOMA-IR, homeostasis model assessment for fasting insulin resistance; LDL, low-density lipoprotein cholesterol; Leu, leuprolide acetate; TG, triglycerides; Tot Chol., total cholesterol.

between that and our study, namely the fact that $66.3 \%$ of subjects in that study had had surgery and were therefore not taking CPA. Indeed, the same authors reported an increase of HDL-cholesterol after removing CPA. Also, $44.9 \%$ of TW were using EV and $42.5 \%$ at higher doses ( 4 $\mathrm{mg}$ ) than we prescribed in our study (26).

The use of CPA in our cohort seemed to negatively impact glucose metabolism with significant increase of Homa-IR. This change in glucose metabolism, already reported in previous studies, may be due to the weak glucocorticoid activity of CPA but also to the slight increase in the waist circumference in the $\mathrm{CPA}+\mathrm{E}$ group. It is well known that the increase of subcutaneous abdominal and visceral fat is associated with insulin resistance and the administration of anti-androgens and estrogens in TW have been shown to increase subcutaneous fat $(27,28,29)$.

In our cohort, both groups showed a progressive increase in body weight with no significant decrease in lean mass and increase in fat mass, and with no significant increases in BMI or WHR. Hip circumferences increased but not significantly in both groups in accordance with female fat distribution as has already been reported by other authors, with increased subcutaneous fat in the gluteofemoral area $(29,30,31,32)$. Our 5 -year prospectively collected data extend and reinforce previous reports 
Table 3 Anthropometric, body composition, bone metabolism and bone mineral density parameters at baseline and during follow-up of GAHT in the two groups of subjects. Data are reported as mean \pm S.D.

\begin{tabular}{|c|c|c|c|c|c|c|c|c|c|c|c|}
\hline \multirow[b]{3}{*}{ Groups } & \multirow[b]{3}{*}{$n$} & \multirow[b]{3}{*}{ Baseline } & \multirow[b]{3}{*}{ Year 1} & \multirow[b]{3}{*}{ Year 3} & \multirow[b]{3}{*}{ Year 5} & \multicolumn{6}{|c|}{ Mixed-design ANOVA results } \\
\hline & & & & & & \multicolumn{2}{|c|}{ Time } & \multicolumn{2}{|c|}{ Treatment } & \multicolumn{2}{|c|}{ Time $\times$ treatment } \\
\hline & & & & & & $\mathrm{F}$ & $P$ & $\mathrm{~F}$ & $P$ & $\begin{array}{l}\mathrm{F} \\
\end{array}$ & $P$ \\
\hline Body weight (kg) & & & & & & 8.191 & 0.0117 & 0.014 & 0.907 & 0.527 & 0.664 \\
\hline $\mathrm{CPA}+\mathrm{E}$ & 25 & $68.3 \pm 11.9$ & $67.4 \pm 10.8$ & $71.5 \pm 10.8$ & $71.6 \pm 14.9$ & & & & & & \\
\hline Leu + E & 25 & $67.6 \pm 9.2$ & $69.6 \pm 10.4$ & $70.2 \pm 10.4$ & $74.4 \pm 12.5$ & & & & & & \\
\hline WC (cm) & & & & & & 2.770 & 0.095 & 0.030 & 0.863 & 0.146 & 0.932 \\
\hline$C P A+E$ & 25 & $78.1 \pm 6.4$ & $79.4 \pm 10.7$ & $82.8 \pm 6.4$ & $82.4 \pm 8.7$ & & & & & & \\
\hline Leu + E & 25 & $79.9 \pm 7.2$ & $80.4 \pm 9.3$ & $82.1 \pm 10.8$ & $82.5 \pm 10.7$ & & & & & & \\
\hline $\mathrm{HC}(\mathrm{cm})$ & & & & & & 3.563 & 0.039 & 0.178 & 0.675 & 0.186 & 0.906 \\
\hline$C P A+E$ & 25 & $93.7 \pm 6.3$ & $95.8 \pm 6.3$ & $100.5 \pm 6.7$ & $97.5 \pm 6.1$ & & & & & & \\
\hline Leu + E & 25 & $97.1 \pm 3.9$ & $97.8 \pm 6.2$ & $98.9 \pm 9.8$ & $101.7 \pm 5.3$ & & & & & & \\
\hline WHR & & & & & & 0.448 & 0.659 & 0.015 & 0.902 & 0.382 & 0.767 \\
\hline$C P A+E$ & 25 & $0.83 \pm 0.06$ & $0.83 \pm 0.07$ & $0.83 \pm 0.05$ & $0.82 \pm 0.08$ & & & & & & \\
\hline Leu + E & 25 & $0.82 \pm 0.07$ & $0.82 \pm 0.07$ & $0.83 \pm 0.07$ & $0.81 \pm 0.05$ & & & & & & \\
\hline Fat (\%) & & & & & & 0.384 & 0.548 & 0.667 & 0.418 & 1.286 & 0.286 \\
\hline$C P A+E$ & 25 & $22.9 \pm 7.3$ & $26.9 \pm 4.6$ & $30.0 \pm 5.2$ & $31.8 \pm 7.4$ & & & & & & \\
\hline Leu + E & 25 & $23.0 \pm 6.1$ & $26.8 \pm 6.4$ & $30.2 \pm 5.2$ & $32.9 \pm 7.7$ & & & & & & \\
\hline $\mathrm{OC}(\mu \mathrm{g} / \mathrm{L})$ & & & & & & 0.591 & 0.461 & 0.017 & 0.898 & 0.972 & 0.410 \\
\hline$C P A+E$ & 25 & $24.7 \pm 10.3$ & $28.2 \pm 15.0$ & $25.2 \pm 8.5$ & $21.4 \pm 7.7$ & & & & & & \\
\hline Leu + E & 25 & $31.7 \pm 14.0$ & $29.6 \pm 9.9$ & $27.4 \pm 8.7$ & $28.2 \pm 14.5$ & & & & & & \\
\hline PTH (pg/mL) & & & & & & 0.766 & 0.495 & 0.036 & 0.850 & 2.650 & 0.054 \\
\hline$C P A+E$ & 25 & $42.1 \pm 16.4$ & $35.4 \pm 8.4$ & $43.0 \pm 12.2$ & $38.4 \pm 14.8$ & & & & & & \\
\hline Leu + E & & $42.6 \pm 19.8$ & $51.9 \pm 18.9$ & $51.2 \pm 21.1$ & $46.9 \pm 22.6$ & & & & & & \\
\hline BAP (UI/L) & & & & & & 0.591 & 0.532 & 0.036 & 0.850 & 1.547 & 0.209 \\
\hline$C P A+E$ & 25 & $15.8 \pm 7.0$ & $13.7 \pm 6.5$ & $12.9 \pm 4.7$ & $10.7 \pm 3.1$ & & & & & & \\
\hline Leu + E & 25 & $17.4 \pm 9.7$ & $16.8 \pm 8.7$ & $15.3 \pm 6.2$ & $16.6 \pm 6.2$ & & & & & & \\
\hline Lumbar BMD (g/cm²) & & & & & & 6.137 & 0.015 & 0.562 & 0.457 & 0.834 & 0.479 \\
\hline $\mathrm{CPA}+\mathrm{E}$ & 25 & $1.0 \pm 0.2$ & $1.0 \pm 0.2$ & $1.1 \pm 0.1$ & $1.1 \pm 0.1$ & & & & & & \\
\hline Leu + E & 25 & $1.1 \pm 0.1$ & $1.1 \pm 0.2$ & $1.1 \pm 0.1$ & $1.1 \pm 0.2$ & & & & & & \\
\hline $\begin{array}{c}\text { Total BMD } \\
\qquad\left(\mathrm{g} / \mathrm{cm}^{2}\right)\end{array}$ & & & & & & 6.092 & 0.008 & 0.621 & 0.434 & 1.163 & 0.331 \\
\hline$C P A+E$ & 25 & $1.2 \pm 0.1$ & $1.2 \pm 0.1$ & $1.2 \pm 0.2$ & $1.1 \pm 0.1$ & & & & & & \\
\hline Leu + E & 25 & $1.1 \pm 0.1$ & $1.1 \pm 0.1$ & $1.1 \pm 0.1$ & $1.2 \pm 0.1$ & & & & & & \\
\hline
\end{tabular}

BAP, bone alkaline phosphatase; BMD, bone mineral density; CPA, cyproterone acetate; $\mathrm{HC}$, hip circumference; Leu, leuprolide acetate; OC, osteocalcin; PTH, parathyroid hormone; WC, waist circumference; WHR, waist/hip ratio.

with shorter follow-ups $(11,33,34)$. It should be noted that variations (increase in body weight, waist and hip circumferences and fat mass) are progressive over 5 years of follow-up although they seem to be faster in the first 3 years of treatment; further studies with longer follow-up will reveal how long those variations are maintained or progress over time. When considering longer-time changes in those anthropometric parameters a comparison with the general population is recommended. For example, in the general Italian population, fat mass is reported to have a $5.1 \%$ increase in both males and female in 10 years (from the ages of 25-34 to 35-44 years old) (35). In our cohort, the increase in fat mass is about double in half the time (9.5\% in 5 years) and thus this difference could be attributed due to the effects of GAHT added to ageing.

Whether the observed metabolic changes in subjects receiving $\mathrm{CPA}+\mathrm{E}$ such as decreased HDL-cholesterol, insulin resistance and body fat mass lead to long-term differences in cardiovascular safety profiles and events between the two regimens remains to be established especially in those subjects that do not wish to undergo GASI and therefore may be using the combined regimen for many years. However, blood pressure, the other relevant player in cardiovascular risk, did not change. In the light of these and of the previous data reported in the literature, intensive counselling on life-style behaviour is mandatory at the commencement of GAHT in TW.

DXA follow-up showed a positive time-effect in lumbar and total body sites without significant differences between the two treatments. We previously reported substantial stability of BMD in TW after 1 year of GAHT with both $\mathrm{CPA}+\mathrm{E}$ and Leu+E (11), whereas other studies indicated an increase $(30,36,37,38)$. While the role of the estrogenic component of GAHT is known, scarce evidence is available regarding the different role of anti-androgen compounds, especially in long-term treatments. However, 
in our cohort both regimens were associated with a good bone profile over time. Because the majority of subjects received $\mathrm{TE}$ it was not possible to assess if the different route of administration of estrogens can modulate the effect of different anti-androgens but this certainly is another good question to be investigated in future studies.

Some limitations of this study should be acknowledged: the number of subjects is not large and this may have led to a statistical type II error. This is a cohort study based on prospectively collected data and this study design has some limitations such as the possible selection bias and the nonrandomised allocation of treatments. For those reasons, a randomised, double-blind, controlled study would be welcomed in the future. More research is needed on the psychological well-being and satisfaction of these treatments in TW. Some strengths should also be acknowledged: our cohort was closely monitored with blood tests and DXA examinations all performed within the same University Hospital facilities, all subjects adhered to the prescribed treatment during the follow-up and they all used a similar formulation of estrogens without the use of ethynylestradiol which is known to potentially interfere with certain metabolic parameters.

In conclusion, with our study, we aimed to compare the metabolic and, anthropometric, bone profiles, hormonal and overall safety of CPA or Leu in combination with E in TW over a period of 5 years. Even if we demonstrated that both treatments are globally effective and without severe adverse events for 5 years of administration, our results could have future clinical implications in the choice of appropriate treatment in particular for those TW not requiring GASI who are therefore looking for long-term GAHT. Subjects treated with $\mathrm{CPA}+\mathrm{E}$ seem to undergo a worsening of the metabolic profile and a slight increase in PRL. Further long-term studies should continue to investigate whether the different metabolic effects of the two regimens may result in a different lifelong safety profile.

\section{Declaration of interest}

The authors declare that there is no conflict of interest that could be perceived as prejudicing the impartiality of the research reported.

\section{Funding}

This research did not receive any specific grant from funding agencies in the public, commercial, or not-for-profit sectors.

\section{Acknowledgements}

The authors thank Julie Norbury for English copy editing and Jacopo Lenzi for statistical analysis supervision.

\section{References}

1 Diagnostic and Statistical Manual of Mental Disorders: DSM-5, 5th ed. Arlington, VA : American Psychiatric Publishing, 2013. (https://doi. org/10.1176/appi.books.9780890425596)

2 Meriggiola MC \& Gava G. Endocrine care of transpeople part II. A review of cross-sex hormonal treatments, outcomes and adverse effects in transwomen. Clinical Endocrinology 201583 607-615. (https://doi.org/10.1111/cen.12754)

3 Tangpricha V, Hannema SE, Irwig MS, Meyer WJ, Safer JD \& Hembree WC. American Association of Clinical Endocrinologists/ Endocrine Society update on transgender medicine: case discussions. Endocrine Practice 201723 1430-1436.

4 Meriggiola MC, Jannini EA, Lenzi A, Maggi M \& Manieri C. Endocrine treatment of transsexual persons: an Endocrine Society Clinical Practice Guideline: commentary from a European perspective. European Journal of Endocrinology 2010162 831-833. (https://doi.org/10.1530/EJE-09-1091)

5 Asscheman H, Giltay EJ, Megens JAJ, de Ronde WP, van Trotsenburg MAA \& Gooren LJG. A long-term follow-up study of mortality in transsexuals receiving treatment with cross-sex hormones. European Journal of Endocrinology 2011164 635-642. (https://doi.org/10.1530/EJE-10-1038)

6 Seal LJ, Franklin S, Richards C, Shishkareva A, Sinclaire C \& Barrett J. Predictive markers for mammoplasty and a comparison of side effect profiles in transwomen taking various hormonal regimens. Journal of Clinical Endocrinology and Metabolism 201297 4422-4428. (https:// doi.org/10.1210/jc.2012-2030)

7 Savidou I, Deutsch M, Soultati AS, Koudouras D, Kafiri G \& Dourakis SP. Hepatotoxicity induced by cyproterone acetate: a report of three cases. World Journal of Gastroenterology 200612 7551-7555. (https://doi.org/10.3748/wjg.v12.i46.7551)

8 van Kesteren PJM, Asscheman H, Megens JAJ \& Gooren LJG. Mortality and morbidity in transsexual subjects treated with crosssex hormones. Clinical Endocrinology 199747 337-342. (https://doi. org/10.1046/j.1365-2265.1997.2601068.x)

9 Cohen-Kettenis PT \& Klink D. Adolescents with gender dysphoria. Best Practice and Research: Clinical Endocrinology and Metabolism 2015 29 485-495. (https://doi.org/10.1016/j.beem.2015.01.004)

10 Wilson AC, Meethal SV, Bowen RL \& Atwood CS. Leuprolide acetate: a drug of diverse clinical applications. Expert Opinion on Investigational Drugs 200716 1851-1863. (https://doi.org/10.1517/13 543784.16.11.1851)

11 Gava G, Cerpolini S, Martelli V, Battista G, Seracchioli R \& Meriggiola MC. Cyproterone acetate vs leuprolide acetate in combination with transdermal oestradiol in transwomen: a comparison of safety and effectiveness. Clinical Endocrinology 2016 85 239-246. (https://doi.org/10.1111/cen.13050)

12 WHO | International Classification of Diseases, 11th Revision (ICD-11). WHO. (available at: http://www.who.int/classifications/icd/en/). Accessed on 25 March 2020.

13 Fanelli F, Gambineri A, Belluomo I, Repaci A, Di Lallo VD, Di Dalmazi G, Mezzullo M, Prontera O, Cuomo G, Zanotti L et al. Androgen profiling by liquid chromatography-tandem mass spectrometry (LC-MS/MS) in healthy normal-weight ovulatory and anovulatory late adolescent and young women. Journal of Clinical Endocrinology and Metabolism 201398 3058-3067. (https://doi. org/10.1210/jc.2013-1381)

14 Bartsch W, Horst HJ, Becker H \& Nehse G. Sex hormone binding globulin binding capacity, testosterone, 5alpha-dihydrotestosterone, oestradiol and prolactin in plasma of patients with prostatic carcinoma under various types of hormonal treatment. Acta Endocrinologica 197785 650-664. (https://doi.org/10.1530/ acta.0.0850650)

15 Gooren LJ, Harmsen-Louman W \& van Kessel H. Follow-up of prolactin levels in long-term oestrogen-treated male-tofemale transsexuals with regard to prolactinoma induction. 
Clinical Endocrinology 198522 201-207. (https://doi. org/10.1111/j.1365-2265.1985.tb01081.x)

16 Asscheman H, Gooren LJ, Assies J, Smits JP \& de Slegte R. Prolactin levels and pituitary enlargement in hormone-treated male-to-female transsexuals. Clinical Endocrinology 198828 583-588. (https://doi. org/10.1111/j.1365-2265.1988.tb03849.x)

17 Cunha FS, Domenice S, Câmara VL, Sircili MHP, Gooren LJG, Mendonça BB \& Costa EMF. Diagnosis of prolactinoma in two male-to-female transsexual subjects following high-dose crosssex hormone therapy. Andrologia 201547 680-684. (https://doi. org/10.1111/and.12317)

18 García-Malpartida K, Martín-Gorgojo A, Rocha M, Gómez-Balaguer M \& Hernández-Mijares A. Prolactinoma induced by estrogen and cyproterone acetate in a male-to-female transsexual. Fertility and Sterility 201094 1097.e13-1097.e15. (https://doi.org/10.1016/j. fertnstert.2010.01.076)

19 Bunck MC, Debono M, Giltay EJ, Verheijen AT, Diamant M \& Gooren LJ. Autonomous prolactin secretion in two male-to-female transgender patients using conventional oestrogen dosages. BMJ Case Reports 20092009 bcr0220091589. (https://doi.org/10.1136/ bcr.02.2009.1589)

20 Sathyapalan T, González S \& Atkin SL. Effect of longterm, high-dose estrogen treatment on prolactin levels: a retrospective analysis. Climacteric 200912 427-430. (https://doi. org/10.1080/13697130902929559)

21 Colizzi M, Costa R, Scaramuzzi F, Palumbo C, Tyropani M, Pace V, Quagliarella L, Brescia F, Natilla LC, Loverro G et al. Concomitant psychiatric problems and hormonal treatment induced metabolic syndrome in gender dysphoria individuals: a 2 year follow-up study. Journal of Psychosomatic Research 201578 399-406. (https://doi. org/10.1016/j.jpsychores.2015.02.001)

22 Giltay EJ, Gooren LJ, Emeis JJ, Kooistra T \& Stehouwer CD. Oral, but not transdermal, administration of estrogens lowers tissuetype plasminogen activator levels in humans without affecting endothelial synthesis. Arteriosclerosis, Thrombosis, and Vascular Biology 200020 1396-1403. (https://doi.org/10.1161/01.atv.20.5.1396)

23 Smith MR, Lee H, McGovern F, Fallon MA, Goode M, Zietman AL \& Finkelstein JS. Metabolic changes during gonadotropin-releasing hormone agonist therapy for prostate cancer: differences from the classic metabolic syndrome. Cancer 2008112 2188-2194. (https:// doi.org/10.1002/cncr.23440)

24 Poyet P \& Labrie F. Comparison of the antiandrogenic/androgenic activities of flutamide, cyproterone acetate and megestrol acetate. Molecular and Cellular Endocrinology 198542 283-288. (https://doi. org/10.1016/0303-7207(85)90059-0)

25 Ott J, Aust S, Promberger R, Huber JC \& Kaufmann U. Cross-sex hormone therapy alters the serum lipid profile: a retrospective cohort study in 169 transsexuals. Journal of Sexual Medicine 20118 2361-2369. (https://doi.org/10.1111/j.1743-6109.2011.02311.x)

26 Denti L, Pasolini G, Cortellini P, Sanfelici L, Benedetti R, Cecchetti A, Ferretti S, Bruschieri L, Ablondi F \& Valenti G. Changes in HDLcholesterol and lipoprotein Lp(a) after 6-month treatment with finasteride in males affected by benign prostatic hyperplasia (BPH). Atherosclerosis 2000152 159-166. (https://doi.org/10.1016/s00219150(99)00442-6)

27 Elbers JMH, Giltay EJ, Teerlink T, Scheffer PG, Asscheman H, Seidell JC \& Gooren LJG. Effects of sex steroids on components of the insulin resistance syndrome in transsexual subjects. Clinical Endocrinology 200358 562-571. (https://doi.org/10.1046/j.13652265.2003.01753.x)

28 Shadid S, Abosi-Appeadu K, De Maertelaere AS, Defreyne J, Veldeman L, Holst JJ, Lapauw B, Vilsbøll T \& T'Sjoen G. Effects of gender-affirming hormone therapy on insulin sensitivity and incretin responses in transgender people. Diabetes Care 202043 411-417. (https://doi.org/10.2337/dc19-1061)

29 Elbers JM, Asscheman H, Seidell JC \& Gooren LJ. Effects of sex steroid hormones on regional fat depots as assessed by magnetic resonance imaging in transsexuals. American Journal of Physiology 1999276 E317-E325. (https://doi.org/10.1152/ ajpendo.1999.276.2.E317)

30 Mueller A, Zollver H, Kronawitter D, Oppelt PG, Claassen T, Hoffmann I, Beckmann MW \& Dittrich R. Body composition and bone mineral density in male-to-female transsexuals during cross-sex hormone therapy using gonadotrophin-releasing hormone agonist. Experimental and Clinical Endocrinology and Diabetes 2011119 95-100. (https://doi.org/10.1055/s-0030-1255074)

31 Gooren LJ. Olympic sports and transsexuals. Asian Journal of Andrology 200810 427-432. (https://doi.org/10.1111/j.17457262.2008.00378.x)

32 Gooren L. Hormone treatment of the adult transsexual patient. Hormone Research 200564 (Supplement 2) 31-36. (https://doi. org $/ 10.1159 / 000087751)$

33 Klaver M, Dekker MJHJ, de Mutsert R, Twisk JWR \& den Heijer M. Cross-sex hormone therapy in transgender persons affects total body weight, body fat and lean body mass: a meta-analysis. Andrologia 201749 e12660. (https://doi.org/10.1111/and.12660)

34 Wierckx K, Van Caenegem E, Schreiner T, Haraldsen I, Fisher AD, Toye K, Kaufman JM \& T'Sjoen G. Cross-sex hormone therapy in trans persons is safe and effective at short-time follow-up: results from the European network for the investigation of gender incongruence. Journal of Sexual Medicine 201411 1999-2011. (https:// doi.org/10.1111/jsm.12571)

35 Barros Almeida Leite C, Di Renzo L, Sinibaldi Salimei P, Gualtieri P, Madalozo Schieferdecker ME, Vilela RM, Ghizoni Teive HA, Frehner C, Taconeli CA, Cabral A et al. Lean body mass: reference values for Italian population between 18 to 88 years old. European Review for Medical and Pharmacological Sciences 201822 7891-7898. (https://doi.org/10.26355/eurrev_201811_16415)

36 Van Caenegem E, Wierckx K, Taes Y, Schreiner T, Vandewalle S, Toye K, Kaufman JM \& T'Sjoen G. Preservation of volumetric bone density and geometry in trans women during cross-sex hormonal therapy: a prospective observational study. Osteoporosis International 201526 35-47. (https://doi.org/10.1007/s00198-0142805-3)

37 Wiepjes CM, de Jongh RT, de Blok CJ, Vlot MC, Lips P, Twisk JW $\&$ den Heijer M. Bone safety during the first ten years of gender-affirming hormonal treatment in transwomen and transmen. Journal of Bone and Mineral Research 201934 447-454. (https://doi. org/10.1002/jbmr.3612)

38 Singh-Ospina N, Maraka S, Rodriguez-Gutierrez R, Davidge-Pitts C, Nippoldt TB, Prokop LJ \& Murad MH. Effect of sex steroids on the bone health of transgender individuals: a systematic review and meta-analysis. Journal of Clinical Endocrinology and Metabolism 2017 102 3904-3913. (https://doi.org/10.1210/jc.2017-01642)

Received 15 April 2020

Revised version received 13 August 2020

Accepted 10 September 2020 